\title{
Reconstruction of quadriceps extensor mechanism at child, three months after "sleeve fracture of patella"
}

\begin{abstract}
Fractures of distal pole of patella are usually inadequate cured and most often unrecognised. Children between the third and sixth year have often been affected by this kind of fracture. This is one of the most frequent types of patella fracture that is found at skeletal immature persons. Injuries are often overlooked on the first medical examination and x-ray scanning is not properly read because relatively small part of bone can be seen while the greater part of patella is cartilaginous. It is necessary, in this case, to do detailed clinical examination. The case of unsuccessful conservatively cured fracture of distal patella pole, at ten years old boy, is shown here. This case lead to appearance of re fracture that happened during running after which the boy hasn't seen orthopaedist for three months. Patella atlas and repressed distal fragment with ligament of patella have been appointed. Reconstructive surgery had been done and has been followed by intensive physical therapy in a period of three months. After treatment period results were; active and passive knee mobility, painless movement as well as returning back to sport activities. Even three months after injury it is possible to have successful reconstruction of re-fracture of distal patella pole at children's age of ten.
\end{abstract}

Volume 2 Issue 4 - 2015

\author{
Salihodzic Nazif \\ Department of Orthopaedics with Traumatology, Bosnia and \\ Herzegovina
}

Correspondence: Salihodzic Nazif, Specialist of orthopedic surgery at Cantonal Hospital Bihac, Bosnia and Herzegovina, Email salihodzic.nazif@gmail.com

Received: February 25, 2015 | Published: April 30, 2015

Keywords: sleeve, fracture of patella

\section{Introduction}

Patella is ossasesamoideum ${ }^{1}$ and important part of quadriceps extensor mechanism. Ossification of immature bone begins in a period from third to sixth year. Percentage of patella fracture at skeletal immature persons is low and makes $6 \%$ of total number of patella fractures. ${ }^{1}$ Moreover, sleeve patella fractures at skeletal immature persons are frequent. It is very easy to make mistake upon making diagnoses with $\mathrm{x}$-ray photograph because very small piece of lower patella pole is usually visible whereas invisible cartilaginous part is much bigger at $\mathrm{x}$-ray photograph and gives us information about extensity of injury. This invisible part could be clearly determined by MRI. ${ }^{2,3}$ Open reposition and fixation are essential in order to have good result at extremely dislocated sleeve fractures of patella. ${ }^{1-9}$ Conservative treatment can be resulted with bad restitution of extensor leg apparatus as well as ossification of patella ligament. ${ }^{6,7}$

\section{Case study}

The patient, who suffered injuries during sport activities, is presented in this work. The patient has felt strong pain in the front part of joint after he had forced extensions from flexion knee position. After his arrival at Emergency service, x-ray photograph has been made (Figure 1). This x-ray shows sleeve type of fracture and during clinical examination certain preservation of extensor apparatus has been determined and at the same time conservatively treatment with immobilisation has been recommended. After four weeks immobilisation period, the patient, with protective bandage, is sent to physical therapy. In the following period physical therapist perceived slow rehabilitation of extension reinforcement as well as presence of swelling two months after the beginning of treatment. The patient continued to walk with dynamic ortho sis and returned to sport activities, although his rehabilitation was not completed. As a result, he felt cracking in the joint during the running. Considering the fact that he couldn't get orthopaedic examination in a place where he is living, he didn't see specialist for three months. In addition, he sees orthopaedic doctor with following difficulties; repeated fracture of distal fracture, high riding patella and full lack of function of extensor leg apparatus. New MRI and x-ray had been taken and it has been decided that reconstruction of extensor leg apparatus must be fixed by surgery.

The operation contained following; presentation of refracture, debridement of distal segment, setting the transosteal stitches and patello- tibial wired disencumberment in strengthened semi flexion. After all, immobilisation with tutor plaster, ina period of three weeks, has been taken. The tutor plaster had so called window for cleaning the wound. Furthermore, an intensive physical therapy proceeded. In one month period of physical therapy, the patient was able to do flexion at 80 degrees and had 20 degrees of extension contracture with minimal active extension. Next month, the patient was able to passively achieve full extension of 90 degrees of flexion, but still extension is slightly strengthened. In the third month, patello- tibial wired disencumberment had been removed by surgery and physical treatment has been continued. In the middle of the fourth month after surgery, painless and full volume of mobility was returned while an active extension was complete (Figure $2 \& 3$ ). The patient says that he has returned to easy sport activities and hasn't got any important difficulties.

\section{Discussion}

Patella fractures are rare at skeletal immature persons and incidence mentioned is rising with years. ${ }^{1}$ They appear at sports which have bigger demands and stress on the extensor apparatus of the leg. This all happens when produced contraction forces perform impulsive extension with leg which is blocked with some kind of obstacle or mechanism of forced extension from flexion position.

A bone, at young person up to the age of six, is protected from injuries with large layer of cartilage. The fact that cartilage constitutes the bigger part of broken fragment leads us toward the fact that $\mathrm{x}$-ray 
never shows signs of sleeve fracture whereas a healing is directed with another protocol. MRI, in these cases, could help to appoint exact diagnoses. Clinical palpable emptiness, lack of extension function as well as "empty" quadriceps, ${ }^{10}$ high riding patella presented on lateral $\mathrm{x}$-ray, ${ }^{1,2,11}$ are signs that indicate fracture of lower pole of patella. Complications after surgery treatment are rare, but sometimes certain aspects are present like; certain lack of flexion, ectopic ossification ${ }^{12}$, hypertrophy of lower patella, and rarely avascular necrosis of the knee cap can occur because vascularisation comes from the front wall of lower pole. ${ }^{1,2,13}$

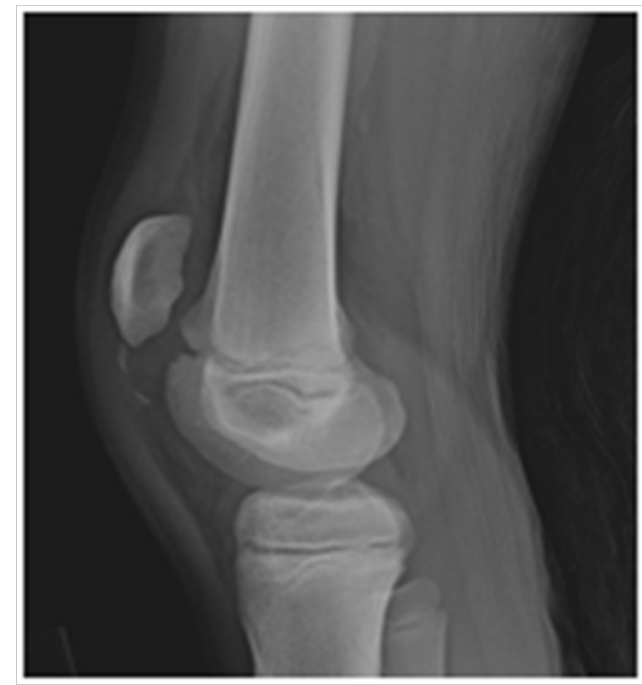

Figure I X - rays of patellar sleeve fracture.

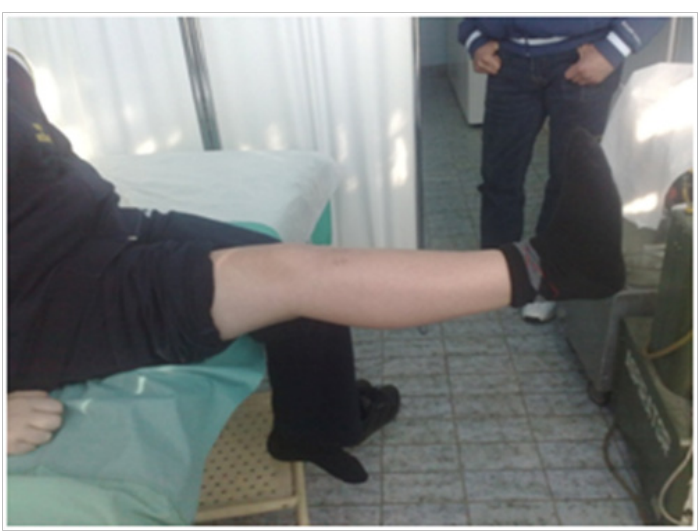

Figure 2 Full extension after treatment of sleeve fracture of patella.

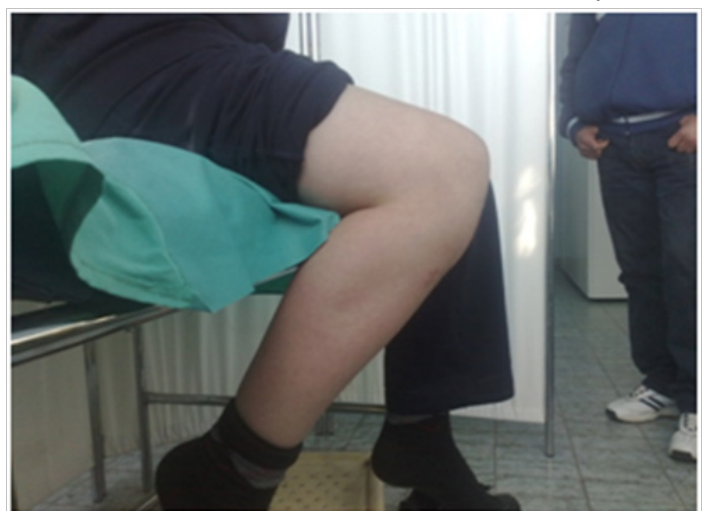

${ }^{1}$ Tiny bone nodes in a sesame size

\section{Conclusion}

Sleeve type of fracture is often overlooked at children because of difficulties during diagnoses procedure and estimation of the function of freshly injured knee, which all is necessary for making correct diagnoses. Treatment is determined according the function of extensor apparatus after injury and $\mathrm{x}$-ray photograph. Reconstruction at unsuccessful conservative treatment is possible, what is presented in this case, where a satisfying result has been achieved.

\section{References}

1. Ray JM, Hendrix J. Incidence, mechanism of injury, and treatment of fractures of the patella in children. J Trauma. 1992;32(4):464-467.

2. Bates DG, Hresko MT, Jaramillo D. Patellar sleeve fracture: demonstration with MR imaging. Radiology. 1994;193(3):825-827.

3. Sponseller PD, Beaty JH. Fractures and dislocations of the knee. In: Rockwood CA (Eds.), Fractures of the patella in children. Lippincott Williams and Wilkins, Philadelphia, USA, 1996;pp. 1284-1290.

4. Wu CD, Huang SC, Liu TK. Sleeve fracture of the patella in children. A report of five cases. Am J Sports Med. 1991;19(5):525-528.

5. Houghton GR, Ackroyd CE. Sleeve fractures of the patella in children: a report of three cases. J Bone Joint Surg Br. 1979;61-B(2):165-168.

6. Bensahel H, Sprung R. Fractures of the patella in children. J Chir (Paris). 1970;99(1):45-54.

7. Wilson JS, Genant HK, Carlsson A, et al. Patellar giant cell tumor. Am J Roentgenol. 1976;127:856-858.

8. Gupta RR, Johnson AM, Moroz L, et al. Patellar sleeve fractures in children: a case report and review of the literature. Am J Orthop (Belle Mead NJ). 2006;35(7):336-338.

9. Kaar TK, Murray P, Cashman WF. Transosseous suturing for sleeve fracture of the patella: case report. Ir J Med Sci. 1993;162(4):148-149.

10. Bruijn JD, Sanders RJ, Jansen BRH. Ossification in the patellar tendon and patella alta following sports injuries in children. Complications of sleeve fractures after conservative treatment. Arch Orthop Trauma Surg. 1993;112(3):157-158.

11. Davidson D, Letts M. Partial sleeve fractures of the tibia in children: an unusual fracture pattern. J Pediatr Orthop. 2002;22(1):36-40.

12. Jacquemier M, Chrestian P, Guys JM, et al. Fracture-avulsions of the patella in children. Chir Pediatr. 1983;24(3):201-204.

13. Shands PA, McQueen DA. Demonstration of avulsion fracture of the inferior pole of the patella by magnetic resonance imaging: a case report. J Bone Joint Surg Am. 1995;77(11):1721-1723.

Figure 3 Flexion after treatment of sleeve fracture of patella. 